\title{
Analysis of the Impact of Information Technology, and Perceived Organizational Justice on Employee Empowerment (Case Study: Payame Noor University of Kermanshah Province)
}

\author{
Bahamn Saeidi pour \\ Department of Educational Sciences, Payame Noor University, Tehran, Iran \\ Email:Bahman_Saeidipour@yahoo.com
}

Doi:10.5901/mjss.2014.v5n20p3037

\begin{abstract}
The aim of this study was to analyze the impact of information technology and perceived organizational justice on employee empowerment. The population of the study consisted of 470 employees of Payame Noor University in Kermanshah province which, between them, 212 people randomly, using Cochran's formula, for example, in the first half of 2014 were selected. This is a correlation study. To collect data, a questionnaire, information technology, Simon \& Soliman (2003), perceived organizational justice questionnaire Neihoff \& Moorman (1993) and inventory Empowerment of Hope Ardalan (2011), using it was. Survey questionnaires showed that the measuring instruments, the validity and reliability are good. Using SPSS and LISREL, data from the study were analyzed. The results showed that perceived organizational justice on the impact of information technology on the role of the mediator is to empower employees.
\end{abstract}

Keywords: information technology, perceived organizational justice, empowerment, structural equation modeling

\section{Introduction}

The use of information technology to increase knowledge and awareness, and enrich the content of the job itself. The use of information technology, and especially information systems, facilitating the control and supervision of the lead, and thus the scope of monitoring managers, as opposed to traditional structures, was considered a limitation, you can spread. Expanding the scope of monitoring, the number of middle-level managers and experts to reduce the number of levels of management in the middle of the organization, will be reduced. The information technology to cut through re-engineering processes, reducing the time to do things and human resources, in the leads. That, ultimately, reduce manpower in the operation, in addition to expanding the scope of monitoring managers through the use of automated systems, the performance of managers and organizations to dramatically upgrade. As mentioned, this will reduce the number of middle-level managers and middle management levels, resulting in a flattening of the leads (Sarafizadeh, 2009). The use of information technology, in addition to the effects on nature and the environment, it also has changed the way organizations compete. Information technology to develop and optimize internal operations of the organization, reduce costs and accelerate domestic production. Reduce costs, the profit opportunity even lower prices for goods and services may also be made. With the speed in getting products to market faster access to the benefits occur. Information technology to support our sales and marketing processes, and speed in marketing, particularly in cases where products and services can reduce costs, and violation of opportunities to be improved (Zargar, 2009). So in today's world, organizations need a plan for your enterprise resources at all levels of management. Appears the main tools used for this preparation, it can be noted that the information technology, will be able to use it, the faster it will go to (Taghavifard et al, 2007). According to the above, it should be asked, what is Information Technology?, Longley and Shain (1985), Information Technology as a collection, organization, storage, and dissemination of information, including audio, video, text or numbers who, by means of computer and telecommunications done. Tarokh and Ommi (2002), Information technology includes a set of techniques and tools that enable the optimization and support systems, and knowledgebased information, also includes the study, design, development, implementation, maintenance and management information systems, computer-based, particularly software applications and computer hardware. According to the above definitions Simon and Soliman (2003), Information technology, including the Internet, personal competence in using computers, knowledge of issues related to the use of computers in assessment.

According to the above should also be said that, Kellogg and Anjali (2003) Information technology also indirectly through its effects on organizational structure (framing jobs and employment relations, and communications organization 
inter and the labor market), the process of justice organizational influence. Lin and Haung (2005), combined with a sense of justice, and in most aspects of life there. This belief is prevalent in our culture that the consequences of any action should be accompanied by justice. Farmer et al (2003) Aspects of Justice plays an important role in organizational life the result makes sense in organization and it is referred to as organizational justice. Aryee et al (2004), Organizational justice perceptions of the fairness of work-related organization. Organizational Justice states that, in what ways should be treated with employees to feel they've been treated fairly with them. It must be asked, what is justice? Before anything could be said that the term organizational justice originally developed by Greenberg (1987), has been employed, in his view, perceptions of organizational justice, fairness in the work-related. And organizational justice suggests that should be treated the way employees feel they have been treated fairly with them. In other words, justice, fair treatment of employees' perceptions of organizational is notion represents employees of the equity and fair play could affect other related variables in the work place. (Akbari et al, 2012). Cropanzano \& Zinta (2000), was twofold justice to distributive justice, procedural justice. D. Kremer (2005), one after the other in the name of justice, interactional justice added. Resulting in Yilmaz and Tasdan (2009) found that organizational justice, the following three types of distributive justice, procedural justice and interactional justice. Williamson and Williams (2011), distributive justice emanates from the Adams' Equity Theory, and the perceived fairness of outcomes deals. Long and Interior (2009), in other words, the organizational reward system. Folger and Cropanzano (1998), although it should be noted that distributive justice is not just limited to the fairness of payments, but also a wide range of organizational outcomes, such as promotion, rewards, punishments and programs employment, benefits, performance evaluations, as well as covers. Procedural justice is a broad concept, the fairness of the procedures used for making facilities and distribution points. Among the principles of procedural justice are impartiality, voice or opportunity to be heard and participate in the decisions cited remarks (Nabatchi et al, 2007). Scientists are two aspects of procedural justice, have been considered: structural aspects and social aspects. This review focuses on the structural aspects that decisions should be taken as a fair look and quality of the social aspects of behavior, interpersonal organization's decision-makers, considered to be a key factor (Greenberg and Baron, 2007).

Considering the above, it should be said that the success of organizations, especially in regard to labor, and to satisfy their needs. Human Resource Capital Framework, the origin of any change and innovation in organizations are considered. For this reason, these organizations must bring justice, promote because a major part in the success of the organization, its goals, and it's your turn, enables employees. Employees' sense of empowerment, which is caused by the disagreement between the manager and the employee with whom he fell from power, and go to support the administrator. (Veten and Cameron, 2008). The first thing you should ask, what is empowerment?, First, the history of the term empowerment of industrial democracy and employee involvement in decision-making organization under grouping, participation and total quality management are concerned. The term in 1980, quickly became the subject of the day, and by theorists such as Conger \& Kanungo (1988), was the expansion (Siglero \& Pearson, 2000). In recent decades, empowerment has become one of the concerns of managers because the managers workload, the speed increased. Therefore, managers must trust their subordinates, in fact, working conditions and competitiveness of enterprises, more than anything else managers, empowering employees get to it. So much so that today, one of marvelous empowerment, human resource development approaches are considered, which leads to the development of human resources and organization. Empowerment is a perpetual motion, and its importance has increased because of developments in business today, along with social changes, technological developments and the demands of the competitive environment, organizations need people who are able to make best use of technology developed to provide innovation to find, and they can improve their products and services. (Smith, 2000). The Conger \& Kanungo (1988), empowerment is a process of strengthening the competence of the people, through the identification of conditions that cause the feeling of powerlessness, of them and try to resolve it with the help of official acts, and In conjunction with informal techniques and also provide enough information for them, the organization helps. Hanvaisch et al (2006), empowerment is a process of division of power between those who work in the organization, have been defined. Empowering employees, managers attempt to remake the most central, decentralized and eliminate bureaucracy in organizations. Empowering people leads to faster and without wasting resources managers and organizations to achieve their goals. Empowerment means that people, organizations and jobs of their own, and their work in the assumption (Abdollahi and Naveh Ebrahim, 2009). Veten and Cameron (2008), empowerment of individuals and the freedom of information to provide to them what they themselves want (corporate responsibility), to do so successfully, rather than forcing them to do, that's what we want to do. Poorrashidi et al (2013), it should be said that empowerment, and foster employees motivated and able to give managers the possibility that the dynamics of the competitive environment, have acted properly, causing the organization to provide competitive advantage. Given the above definitions, empowerment of many empirical studies in this area to date, by scientists such as Mishra \& Spritzer (1998), and it was found that empowerment has five major aspects of the 
organization, feelings of competence, perceived choice, perceived efficacy, sense of meaning and a sense of trust in others. Ardalan (2011) found that empowerment has 7, as follows: improve the quality of staff performance (means increased production and productivity, increase quality, reduce cost, etc.); independence and freedom of employees (meaning influence the individual, in control of your job position, freedom, expression and the right to vote in notes), increase knowledge and awareness (the knowledge refers to the form of documents, laws, instructions, methods, procedures and values are available), an increase in job opportunities (to note that increased diversity job done in various forms., when the information people need to do, to have, it alone can perform one or several tasks simultaneously), increase staff making decisions (on this point, the organization of the human person entitled, in the of different organizations. because it can not be denied that the decision by various organizations, employees and citizens to various forms of influence and in this sense, it must be To distinguish them, we are able to participate in decision-making, selfdetermination involved in), enhanced employee self-control (the tendency of employees to participate in decision-making, goal setting and work in a manner of autonomy, and without caring for others), and develop professional staff (to the point that, in the new leader should provide an environment that allows everyone to learn, grows, develop and job share) Given the above, in the end it must be said that at present, according to information technology, to achieve the goals necessary and inevitable. As the rapid development of technology, all aspects of the organization are somehow influenced the rapid changes in technology that make business work, facing forward toward dramatic changes, and this, drastic changes in the skills needed by individuals, organizations and users have created. On the other hand, its employees, such information is one of the most important resources of the organization, which has, according to them to achieve their goals, it is essential and undeniable, so that could be cited, overall survival and survival of organizations depends on the quality and capabilities of this important factor because it is the workforce that creates formidable organization. This will enable the staff to do your homework well. Managers who want to empower employees to controls, restrictions aside, and justice will literally, be established between them. In other words, to promote the empowerment of employees is essential that organizations in the establishment and development of organizational justice in the workplace undertake efforts. According to the researchers in a broad and comprehensive review of the research, which seeks to answer the question: Is information technology and perceived organizational justice on employee empowerment, Payame Noor University in Kermanshah, impact there? Or not

Finally, an example of research that, in relation to the subject in the country and abroad, has been delivered. Samimi et al (2013), examines the impact of information and communication technologies on organizational justice began. The results show that ICT-based organizational justice is due. Sarboland and Makhlooghi (2013), Oliayi(2012), Dianati (2009), examines the relationship between information technology and employee empowerment began. The results showed that, between information technology and employee empowerment, there is a significant relationship. Nazemi al (2013), Heidaripoor and kamalian (2012), examines the relationship between organizational justice, and empowerment of employees paid. The results showed that, between perceived organizational justice and empowerment of employees, there is a significant relationship. Ghasemi (2012); Fallahi (2010), Sartipi Yarahmadi (2009); Mazidabadi Farahani (2004), in a study of the impact of information technology on employee empowerment began. Results showed that information technology has the effect of empowering employees. Özyer et al (2014), Seyed Danesh and Zamani (2012), and Karimi and Rahman (2012), the study examines the impact of perceived organizational justice, the empowerment of employees paid. Results showed that perceived organizational justice on employee empowerment is effective. Alvandi et al (2014) and Kamalian et al (2010) examined the relationship between organizational justice and empowerment of employees, paid. The results showed that, between perceived organizational justice, and there is a significant relationship between employee empowerment. Dehaghani and MirhAdi (2013), Patrick (2012), the study examines the impact of information technology on perceived organizational justice began. Results showed that information technology on perceived organizational justice is effective. Naser Alraja and Alomiam (2013), and Qudah and and Melhem (2011), the study examines the impact of information technology on employee empowerment began. Results showed that information technology on employee empowerment, effective. According to the research, research hypotheses, as follows. Should be noted that the following hypotheses, each of the variables separately, have been investigated.

Hypothesis1: information technology, organizational justice, perceived affect.

Hypothesis2: perceived organizational justice on employee empowerment, impact.

Hypothesis3: information technology, the empowerment of employees has an impact.

Hypothesis4: perceived organizational justice, the impact of information technology on employee empowerment, the role of mediator. 


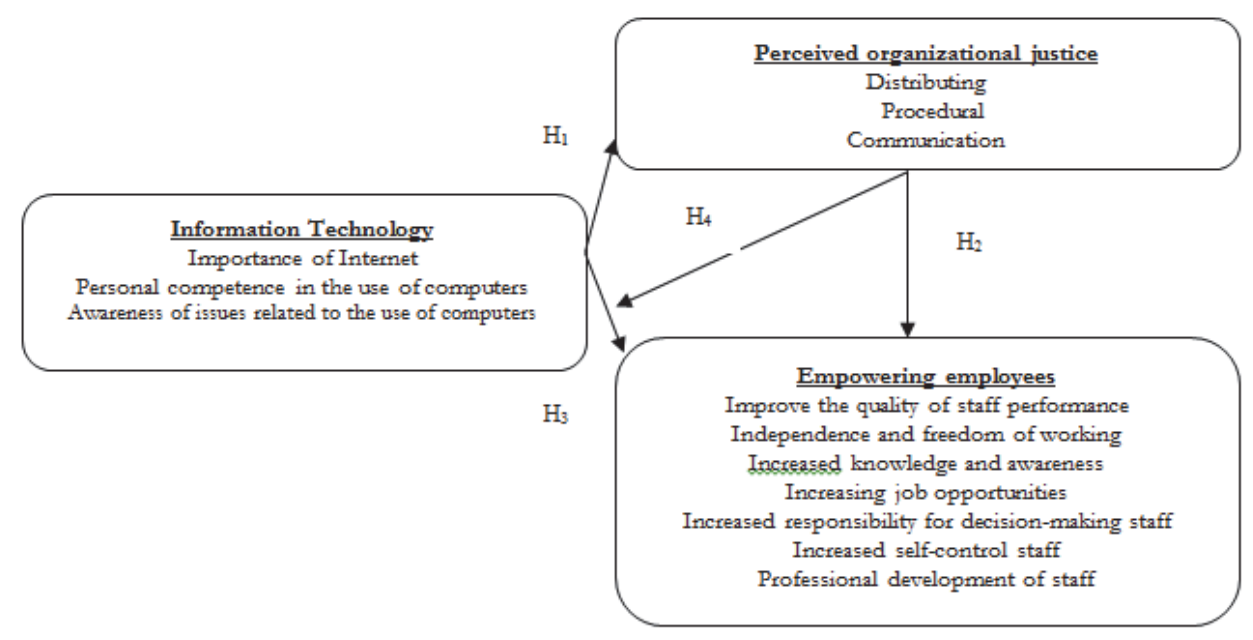

Figure 1: Conceptual model of research

\section{Research Method}

In this study, the purpose of the research, and the method of data collection is a correlation. The study included 470 employees PNU Kermanshah Province, said. Sample, according to Cochran formula, 210 set, was randomly selected individuals. To collect data, a questionnaire, information technology, Simon \& Soliman (2003), which consists of six questions, and perceived organizational justice questionnaire Neihoff \& Moorman (1993), which consists of 20 questions and the questionnaire hope empowerment of Ardalan (2011), which consisted of 26 questions, was used. In this study, to determine the validity of the measuring instruments, the validity of the content, with the other studies, and literature related to the topic of localization, and the ability to measure the desired option in the questionnaire. By a group of university professors, were confirmed. To determine construct validity, factor analysis was used, the results suggest that, once all the items on 5/0 factor that indicates the validity of the measurement instrument. To determine reliability, internal consistency with the help of software SPSS, and Cronbach's alpha coefficients for the different variables described in Table 1 were obtained by questionnaire.

Table1. Alpha coefficient results

\begin{tabular}{|c|c|c|c|c|}
\hline Total Factor & Empowerment of employees & Perceived organizational justice & Information Technology & \\
\hline 0.88 & 0.90 & 0.87 & 0.88 & Cronbach's alpha \\
\hline
\end{tabular}

Table2. The demographic characteristics of the sample

\begin{tabular}{|c|c|c|c|c|c|}
\hline Details & \multicolumn{5}{|c|}{ Group (percent) } \\
\hline Gender & \multicolumn{3}{|c|}{ Men $(0.75)$} & \multicolumn{2}{|c|}{ Women $(0.25)$} \\
\hline Age & Below 27 years $(0.05)$ & $33-27(0.30)$ & $34-40(0.35)$ & $50-41(0.25)$ & Upper $51(0.05)$ \\
\hline Academic education & Under diploma (0.02) & Associate degree $(0.16)$ & $\mathrm{BA}(0.71)$ & \multicolumn{2}{|c|}{ Master's degree or higher $(0.11)$} \\
\hline Years of service & Less than 1 year $(0.20)$ & 1-2year $(0.35)$ & $2-315(0.15)$ & $3-4$ year $(0.25)$ & Upper 4 year $(0.05)$ \\
\hline
\end{tabular}

\section{Results}

In this study, the analysis in this research, the software SPSS (stepwise linear regression), and to test the conceptual model of this study has been used Lisrel. 
Table 3. Relationships between variables and hypotheses

\begin{tabular}{|c|c|c|c|c|c|}
\hline Description & $\begin{array}{c}\text { The first } \\
\text { hypothesis }\end{array}$ & $\begin{array}{l}\text { The second } \\
\text { hypothesis }\end{array}$ & $\begin{array}{c}\text { The third } \\
\text { hypothesis }\end{array}$ & \multicolumn{2}{|c|}{$\begin{array}{l}\text { The fourth } \\
\text { hypothesis }\end{array}$} \\
\hline Type of Relationship & Linear (straight) & Linear (straight) & Linear (straight) & \multicolumn{2}{|c|}{ Step by Step } \\
\hline Error level & 0.05 & 0.05 & 0.05 & \multicolumn{2}{|c|}{0.05} \\
\hline Number (N) & 212 & 212 & 212 & \multicolumn{2}{|r|}{212} \\
\hline Value (R) & 0.191 & 0.222 & 0.181 & \multicolumn{2}{|c|}{0.263} \\
\hline Value $\left(\mathbf{R}^{2}\right)$ & 0.036 & 0.049 & 0.033 & \multicolumn{2}{|c|}{0.109} \\
\hline Value $\left(\overline{\mathrm{R}}^{2}\right)$ & 0.032 & 0.045 & 0.028 & \multicolumn{2}{|c|}{0.099} \\
\hline Ratio (F) & 7.911 & 10.859 & 7.073 & \multicolumn{2}{|r|}{7.745} \\
\hline \multirow{2}{*}{$\beta$} & \multirow{2}{*}{0.194} & \multirow{2}{*}{0.222} & \multirow{2}{*}{0.181} & & POJ 0.194 \\
\hline & & & & & IT 0.143 \\
\hline \multirow{2}{*}{ p-value } & \multirow{2}{*}{0.005} & \multirow{2}{*}{0.001} & \multirow{2}{*}{0.008} & \multirow{2}{*}{0.000} & POJ 0.005 \\
\hline & & & & & IT 0.036 \\
\hline Level of confidence & 0.95 & 0.95 & 0.95 & \multicolumn{2}{|r|}{0.95} \\
\hline $\begin{array}{l}\text { Confirmed } \\
\text { hypothesis }\end{array}$ & $\mathrm{H}_{1}$ & $\mathrm{H}_{1}$ & $\mathrm{H}_{1}$ & \multicolumn{2}{|r|}{$\mathrm{H}_{1}$} \\
\hline
\end{tabular}

The results of the first hypothesis suggests that information technology on perceived organizational justice, according to the 0.005 meaningful and acceptable level of error $(0.05)$, and 0.95 effective is significant. That is, the hypothesis $\mathrm{H} 1$ that expresses effects confirms placed.

The results of the second hypothesis, suggesting that, perceived organizational justice, the empowerment of employees, according to the 0.001 meaningful and acceptable level of error (0.05), and 0.95 with a mean effect is significant. le, hypotheses $\mathrm{H} 1$, indicating effect, be approved.

The results of the third hypothesis, suggesting that information technology-based Empower employees with regard to the level of significance 0.008 , and the acceptable level of error $(0.05)$, and 0.95 with a mean effect is significant. That is, the hypothesis $\mathrm{H} 1$, which shows the effect of the agreement is approved.

The findings of the fourth hypothesis, suggests that, perceived organizational justice, the impact of information technology on employee empowerment, the role of the mediator?

According to the first hypothesis, information technology alone into the equation, which is 0/191 its impact on perceived organizational justice, and the difference is significant. According to the second hypothesis, perceived organizational justice, which alone enters the equation, the impact on employee empowerment 0.263 , and the difference is significant. With regard to the third hypothesis, information technology, alone into the equation, the impact on employee empowerment 0.181 , and the difference is significant. Finally, perceived organizational justice, and information technology are entered into the equation, the effects on both the Empowerment of 0.263 , and is statistically significant, these variables show that is, the overlap because of the fact that both the most and least effective, and empowering employees, respectively, perceived organizational justice (0.194), and Information Technology (0.143 respectively). So it must be said, can be perceived organizational justice, the value of (0.194) on Empowerment of influence, but the fact that information technology can be, the amount $(0.143)$ on empowerment employees will be impacted. Thus, perceived organizational justice variables, as can mediate the effects of information technology on employee empowerment, increase and enhance the 0.263 . The fourth hypothesis is confirmed. 


\subsection{Structural equation modeling}

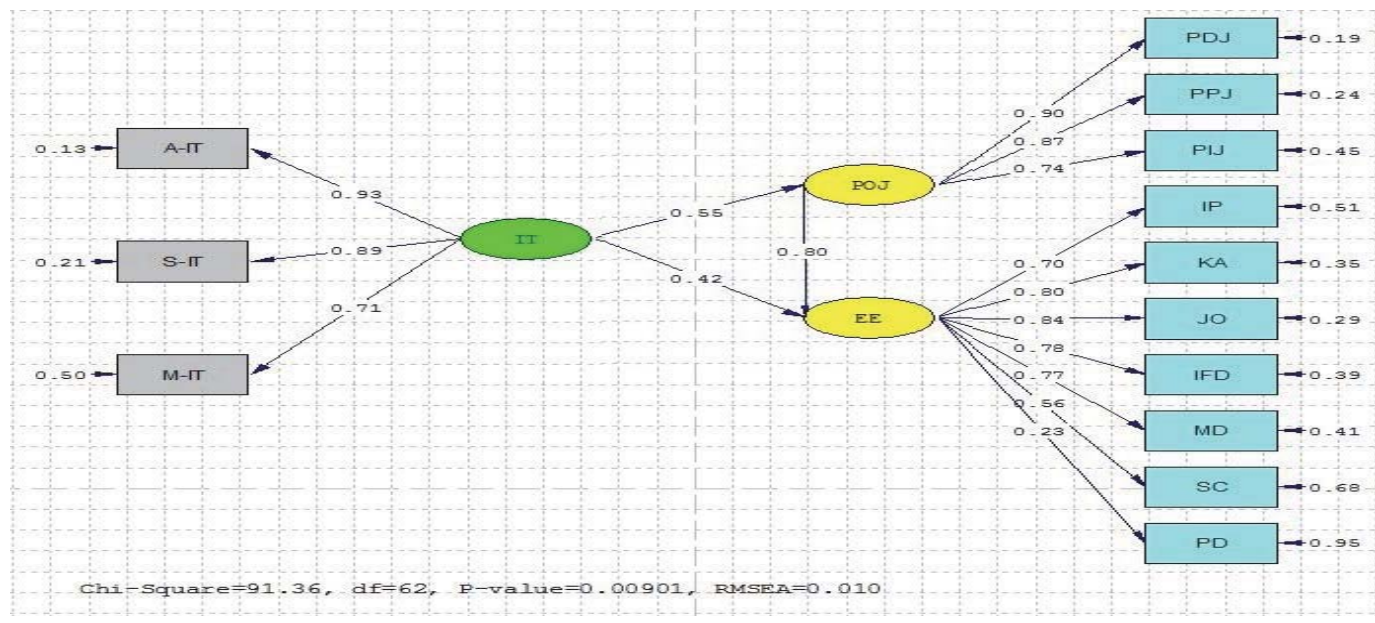

Fig 2. Standard structural equation model: information technology ((IT, perceived organizational justice (POJ) and employee empowerment (EE)

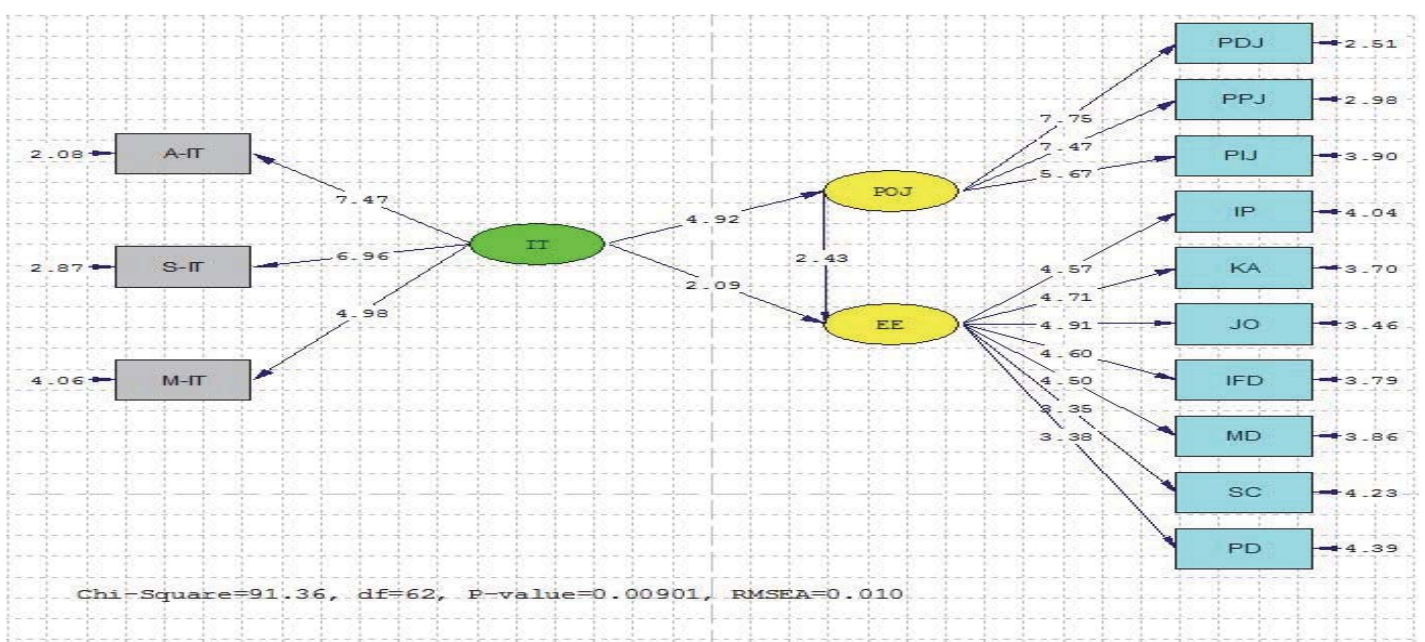

Fig 3. Coefficients between information technology ((IT, perceived organizational justice (POJ) and employee empowerment (EE)

The results show that the Chi square value of 91.36 , and the significant level 0.005 not significant, given that, if the amount is significant chi-square indicates the difference between model and data, and indicates a poor fit of the model (Kalantari, 2009), so in this study, given the lack of significant Chi square test can be said that the model fit was acceptable. Root mean square error of approximation is also an index (RMSEA), the goodness-of-fit index (GFI), respectively, the amounts 0.026 , and 0.92 represents an optimal matching between the structural model (the model assumed accordingly), the experimental data are provided, and can be a suitable model for a structure to be associated with empowerment. Hence the emphasis on structural equation model fit is designed for the Empowerment of employees, and proper fit, represent a structural equation modeling, with emphasis on information technology, and perceived organizational justice, and empowering employees, the university light province of Kermanshah. Other indicators of the model include: NFI (soft fitness index); NNFI (soft notfitness index); RMSR (root mean square residual index) and RFI 
(right of association), and CFI (index comparative fit), such that the model fit is good, the amount of RFI, CFI, NNFI, NFI greater than 0.90, and the RMSR less than 0.05 , and finally the $x 2 /$ df as less is better (Kalantari, 2009). The results in Table 4 are given the values of the indices.

Table 4. This model parameters

\begin{tabular}{|c|l|c|}
\hline Index & Measure & Current Status \\
\hline $\mathbf{X} 2$ & difference between the expected and observed frequency & 91.36 \\
\hline df & greater than zero & 62 \\
\hline $\mathbf{X}^{2} / \mathrm{df}$ & $2 \leq \mathrm{X}^{2} / \mathrm{df} \leq 0$ & 1.47 \\
\hline RFI & more than 0.90 & 0.94 \\
\hline CFI & more than 0.90 & 0.96 \\
\hline NNFI & more than 0.90 & 0.92 \\
\hline NFI & more than 0.90 & 0.91 \\
\hline RMSR & less than 0.05 & 0.026 \\
\hline
\end{tabular}

Table 5. Direct and indirect effects of variables on each other

\begin{tabular}{|c|c|c|c|c|c|c|c|c|c|}
\hline \multirow{2}{*}{ Relations } & \multicolumn{3}{|c|}{ Direct effects } & \multicolumn{3}{c|}{ Indirect effects } & \multicolumn{3}{c|}{ Total effect } \\
\cline { 2 - 9 } & Structural coefficient & $\mathrm{t}$ & Significant & Structural coefficient & $\mathrm{t}$ & Significant & Structural coefficient & $\mathrm{t}$ & Significant \\
\hline $\begin{array}{c}\text { IT } \\
\text { POJ }\end{array}$ & 0.55 & 4.92 & Significant & --- & --- & -- & 0.51 & 4.92 & Significant \\
\hline $\begin{array}{c}\text { POJ } \\
\downarrow \\
\text { EE }\end{array}$ & 0.80 & 2.43 & Significant & --- & -- & -- & 0.77 & 2.43 & Significant \\
\hline $\begin{array}{c}\text { IT } \\
\downarrow\end{array}$ & 0.42 & 2.09 & Significant & 0.44 & 5.08 & Significant & 0.18 & 7.17 & Significant \\
\hline
\end{tabular}

According to Table 5, the direct effect of changing technology on perceived organizational justice, 0.55 , and the coefficient is significant according to t-statistics. See that variable indirect effect of information technology on organizational justice is perceived. More direct effect on perceived organizational justice on employee empowerment was measured against $0 / 80$ that this effect is significant according to t-statistics, again we see that, perceived organizational justice on employee empowerment indirect effect nothing. Finally, the direct effect of changing technology on employee empowerment, equal 0.42 that, according to the t-statistics of the coefficients are significant. On the other hand, we see that the effect of varying pieces of information technologies, to empower employees to 0.44 that, according to the tstatistics of the coefficients are significant. The effect of changing technology on employee empowerment is 0.18 , is significant. For the fourth hypothesis, it must be said, on the one hand, and since the results of the structural model analysis showed that perceived organizational justice, information technology, has a direct and significant impact, as well as perceived organizational justice on employee empowerment significant positive impact. As a result of the mediation role of perceived organizational justice on the relationship between information technology and empowering employees, was supported, so that the indirect impact of information technology on employee empowerment and the role of perceived organizational justice (effect Normal $=0.44$ ), the greater the impact of information technology on employee empowerment (direct effect $=0.42$ ) is.

\section{Discussion and Conclusion}

Information technology, is highly regarded in different countries. So much so that most countries have invested heavily in this area. This paper tries to analyze the effects of applying information technology, and perceived organizational justice on employee empowerment by Payame Noor University in Kermanshah. The results of the first hypothesis of this study showed that the dimensions of information technology on perceived organizational justice, the impact is significant. The use of information technology, in line with perceived organizational justice, that will lead to beneficial results, such as can be noted in several cases. Meanwhile, the use of information technology, a change in job skills are, therefore, in this 
case, employee training, the more important this becomes. On the other hand, it should be noted that the efficiency of the use of information technology, creativity, job satisfaction, and maximize flexibility. In general, the development of information technology, various aspects of perceived organizational justice, influence, and as a strong support for justice is applied. The use of information technology, the perceived organizational justice, which leads to increased productivity. This hypothesis is supported by the research results, the Samimi and colleagues (2013), Dehaghani and MirhAdi (2013) and Patrick (2012) in walking distance. In the second hypothesis, the significant impact of perceived organizational justice on employee empowerment confirmed. Based on these findings, we can conclude that, Payame Noor University in Kermanshah Province, which is a service organization offering services for cultural, educational, and if he wants to the university (eg the Islamic Azad University)، The services it offers, will continue to be a focus for empowering employees, because the quality of work performance, as well as their knowledge increases, employee autonomy and freedom to find something better in the workplace, and in decided against the will of the responsibility will also be able to control their work environment, they get better jobs, and ultimately enable the development of professional staff, will. But it must be said that, regardless of the organizational justice, empowerment can not happen, because it justice employees with a work environment, deals, Marami (1999), so that if an employee thinks that his organization has no justice, his performance at work will decrease, and therefore the performance is reduced. That is why it is said to present any general organizational justice, it will get better, so it is no presence. So the university, it is suggested that, to increase the level of employee empowerment indicators, the situation of justice in their organizations pay more attention. The results of this theory, together with the investigation by the Nazemi and colleagues (2013), Heidaripoor and Kamalian (2012); Özyer et al (2014), Alvandi et al (2014), Seyed Danesh and Zamani2 (2012); Karimi and Rahman (2012), kamalian et al (2010) was to correspond.

The third hypothesis of this study, the dimensions of information technology to empower employees, review the results of the test showed a significant influence on each other. Based on the findings, we can conclude that, Payame Noor University in Kermanshah, should pay great attention to the empowerment of employees, taking into account the role and impact of information technology, which is based on the quality of performance and tone, and Cameron (2008) argued that the use of information technology within an organization pursuant to minimize human error in the information processing network, speed up customer service, and most importantly, increase customer satisfaction there. In the next knowledge workers, Vares (2008) found that the application of information technology to increase knowledge and awareness of employees, an organization for communications easier, more accurate and less expensive, and the other is that of reducing human error in data processing networks finds. In the career development and grandchildren (Abdollahi and Naveh Ebrahim, 2009), found that the use of information technology, the production of new employment opportunities, and the underlying fundamental changes in many other jobs will be. After independence and freedom of action and Goodarzi and Gaminian (2010) also found that the use of information technology, and in particular, information systems, to facilitate the control and supervision of the works, and the scope of supervisory directors, unlike the structures tradition, was considered a limitation may be extended. Expanding the scope of monitoring, the number of middle-level managers and experts to reduce, and thereby the number of management levels in the reduced sections. After making decisions Sarafizadeh (2009) also found that the staff, about the organization and how it functions, the more they will be able to take better decisions, and this increased responsibility for decision-making, the staff will be a shortage of data using information technology in organizations and decision support tool has been fixed. Self-control in the next, and Goodarzi and Gaminian (2010) believed that the use of information technology, internal control system is triggered and, accordingly, the people themselves are evaluated. Sarafizadeh (2009), using information technology, to increase knowledge and awareness of staff, and the richer the content of jobs leads. Knowledge, has mastered their professional organizations, and if a famous saying, "knowledge is power", is accepted, then, can we say that, in organizations where information technology is impressive, employees will have more power. It may be concluded that the use of information technology to develop professional staff, will be

Finally, according to the above, it should be said that an organization should be the role and impact of information technology on the organization aware. And technology, empowerment and satisfaction of their employees use. However, sometimes the staff, the applied information technology, will resist, because the technology will be used against them, but this resistance is natural technology. Hence the need to staff about the benefits of implementing new systems, to acquire the necessary knowledge. If employees know that information technology work to eliminate the risk and simplify tedious tasks to be handled, not only did not resist, but in this case, loyalty to the organization, working pride and job satisfaction increases. The assumption is, the investigation led by the Oliayi (2012); Sarboland and Makhlooghi (2013); Ghasemi (2012); Fallahi (2010), Sartipi Yarahmadi (2009), Dianati (2009); Yazdanpanah (2005); Mazidabadi Farahani (2004); Naser Alraja and Alomiam (2013) and Qudah and and Melhem (2011) in walking distance. 
The fourth research hypothesis, the mediating role of perceived organizational justice, the impact of information technology on employee empowerment was measured, and the results showed that the impact of information technology on employee empowerment, perceived organizational justice, role of mediator is, in other words, perceived organizational justice variables can have a positive impact on information technology, the empowerment of employees, increase. So Payame Noor University in Kermanshah organizations, to promote the empowerment of employees, should be perceived organizational justice, mind, and this can also be important, with regard to information technology, realized. Since the conclusion of the first hypothesis stated, information technology can be a significant effect on perceived organizational justice is. Finally, with regard to the results of the structural equation model, we can say that these results correspond to regression test, and it confirmed the research hypotheses. In other words, the direct effect of information technology on perceived organizational justice on employee empowerment and perceived organizational justice has a direct impact on employee empowerment, and the indirect impact of information technology on employee empowerment was confirmed. And with the approval of the conceptual model, we can make it as a model that can guide scientific research and practical basis for future be, considered.

\section{Acknowledgement}

This article is taken from a research project by Payame Noor University (PNU), has been funded.

\section{References}

Abdollahi, B and Naveh Ebrahim A., (2009). Empowering staff: Golden Key HRM. Tehran, publication editing.

Akbari, P, Sharafi, M and Vatandost, T., (2012). A Study of the Relationship between Perceived Organizational Justice and Social Capital of Staff (Case Study: Physical Education General Department of llam province), International Journal of Sport Studies. 2 (9), pp. 455-464, 2012

Alvandi, M, Foroghi, $\mathrm{H}$ and Suleymani, M., (2014). The Relationship between the Organizational Justice and Empowerment of the Employees of Hamadan Sport and Youth Government Offices in Iran, International Research Journal of Applied and Basic Sciences, 8 (2), pp. 146-149

Ardalan, O., (2011). The effects of information technology, the empowerment of employees (Case Study: Kermanshah Province West regional power distribution companies). MS Thesis Executive Management, Islamic Azad University, Kermanshah

Aryee, S,et all (2004). Exchange fairness and employee performance: An examination of the relationship between organizational politics and procedural justice. Organizational Behavior and Human Decision Processes, 94 (1), PP 1-14.

Conger JA, Kanungo RN. (1988) the Empowerment Process: Integrating Theory and Practice. Academy Of Management Review; 13 (3), pp.471-482.

Dehaghani, M.V and MirhAdi, F.S., (2013). Impressing Organizational Justice Rules Based on Information Technology (Case study: Telecommunication Company). International Journal of Academic Research in Accounting, Finance and Management Sciences. 3 (4), pp.197-207

DeCremer, D, (2005). Procedural and distributive justice effects moderated by organizational identification. Journal of Managerial Psychology, 20 (1) , pp. 4-13.

Dianati, M., (2009). The role of information and communication technologies in empowering employees and Broadcasting, in Tehran, Iran. MS Thesis, Islamic Azad University Roodehen

Cropanzano, R \& Zinta. B.S., (2000). The relationship of emotional exhaustion to work attitudes, job performance rating, and organizational citizenship behaviors " fifteenth annual conference of society for industrial and organizational psychology in new Orleans, April, pp. 13-16

Farmer S.; Beehr, T., and Love K (2003).Becoming an Undercover Police Officer: A Note on Fairness Perceptions, Behavior, and Attitudes, Journal of Organizational Behavior. 24 (4), pp373-387.

Fallahi, A., (2010). The role of information technology in empowering employees, Bank Melli Iran, Shiraz. First International Conference on Innovation and Management.

Folger, R and Cropanzano, R., (1998). Organizational Justice and human resource management, sage, Thousand Oaks, CA.

Ghasemi, M., (2012). Effects of information technology on employee empowerment, and provide optimal reading case study: China factory of the company. Master Thesis Management (MBA), University of Science and Culture.

Greenberg, J., \& Baron, R.A. (2000). Behavior in organizations, 7th ed. Upper Saddle River, NJ: Prentice-Hall.

Greenberg, J., (1987). Reactions to procedural injustice in payment distributions: Do the means justify the ends?" Journal of Applied Psychology, 72. Pp.55-61

Goodarzi, A and Gominian, V., (2010), Principles, principles and theories of climate and organizational culture, publications SID of the unit Isfahan

Hanvaisch S, Sivakumar K, Tomas G. (2006). The Relation of Learning and Memory with Organizational Performance. Journal of the Academy of Marketing Science, 27 (4): 411-427

Heidaripoor, R and kamalian, A.R., (2012). Examine the relationship between organizational justice and psychological empowerment. 
Journals of organizational culture Management, 10 (25), pp. 201-175

Kalantari, K., (2009). Structural Equation Modeling in Social Research - economics. Tehran: Publication of Saba.

Kamalian, A.R, Yaghoubi, N.M and Moloudi, J., (2010). Survey of Relationship between Organizational Justice and Empowerment (A Case Study). European Journal of Economics, Finance and Administrative Sciences, 26 (2010), PP.165-171

Karim, F and Rehman, O., (2012). Impact of Job Satisfaction, Perceived Organizational Justice and Employee Empowerment on Organizational Commitment in Semi-Government Organizations of Pakistan. Journal of Business Studies Quarterly, 3 (4), pp. 92104

Kellogg, W.W.A and, Anjali. M., (2003). Environmental Justice and Information Technologies: Overcoming the Information-Access Paradox in Urban Communities, Public Administration Review, 63 (5), PP.573-585.

Longley, D and Shain, M (1985). Dictionary of Information Technology, 2nd Edition, maemillan press Lts. 1985

Lin shu-chi , haung yin- mei(2005). The role of social capital in the relationship between human capital and career mobility: Moderator or mediator?, Journal of Intellectual Capital, 6 (2), pp. 191-205.

Loong, L.K and Khong, K.W (2009). Organizational Commitment: The Study of Organizational Justice and Leader Member Exchange (LMX)Among Auditors in Malaysia, International Journal of Business and Information, 4 (2), pp.161-198.

Marami, A.R., (1999). Comparison of justice concept add Nottahari, Shariati and Seyed Qotb. Press center of Islamic Master

Mazidabadi Farahani, A.H., (2004). The effect of information technology on job empowerment, "a study of the social security organization of Qom" .thesis M.A, Tehran University,

Mishra, A.K \& Spritzer, G.M; Explaining how Survivors Respond to Downsizing: The Role of Trust, Empowerment, Justice and Work Redesign, academy of management review, 1998, 23 (3), Pp. 567-588.

Nabatchi, Tina, Lisa, Blomgren Bingham and David H. Good(2007). "Organizational justice and workplace mediation: a six-factor model", International Journal of Conflict Management,18 (2), pp.148-174.

Naser Alraja, M and Alomiam, N.R., (2013). THE Effect of Information Technology in Empowerment Public Sector Employees: A Field Study, Institute of Interdisciplinary Business Research, 5 (1), PP. 805-815

Nazemi, M, Alizadeh Golrizi, A and Koozehchian, H., (2013). Examine the relationship between organizational justice and the empowerment of the physical education department Razavi Khorasan Province. Journal of Sport Management Studies, 5 (18), pp 175-188

Neihoff, B.P., \& Moorman, R.H., (1993). Justice as a mediator of the relationship between method of monitoring and organizational citizenship behavior. Academy of Management Journal, 36, pp. 527-556.

Özyer, K, Azizoğlu, Ö, Cindiloglu, M and Eryigit, R., (2014). Does Organizational Justice Have Effect on Empowerment? A Study in Turkish Business Context, International The 2nd IBEA - International Conference on Business, Economics and Accounting, Hong Kong, 26 - 28 March 2014

Oliayi, K., (2012). The role of information technology in vocational education empowerment organization. MS Thesis, University of Sistan and Baluchestan

Poole W.L., (.2007). "Organizational Justice as a Framework for Understanding Union-Management Relations in Education. Canadian Journal of Education, 30 (3), pp.725-748.

Patrick, H.A., (2012). Commitment of Information Technology Employees in Relation to Perceived Organizational Justice, The IUP Journal of Organizational Behavior, 11, (3), pp. 23-40.

Poorrashidi, R; Qorbani Nejad Koohbanani, M and Maleki Koohbanani, S., (2013). Recommendations on the role of education and empowerment. Virtual Congress of Rah Avaran afferent

Qudah, S and Melhem, Y ., (2011). Impact of Information and Information Technology on Empowerment of Employees Private School Sector in Northern Region in Jordan, Journal of Emerging Trends in Economics and Management Sciences (JETEMS), 2 (1), PP. $40-48$

Samimi, A, Tavakoli Roozbehani, N, Mosamamifar, F and Azimi A.A., (2013). Effects of information and communication technologies on organizational justice. Eleventh International Conference on Management

Sartipi Yarahmadi, R., (2009). Application of information technology in enabling employees Islamic Azad University Library District 5. MS Thesis, Islamic Azad University, Hamedan Branch.

Sarafizadeh, A., (2009). Information technology in organizations (bases and Applications), (First Edition), Tehran: Mir Publishers.

Sarboland, K and Makhlooghi A., (2013). Effects of information technology on job empowerment, Case West regional electricity distribution company in the province. National Conference on Management of business.

Seyed Danesh, S.Y and Zamani, A., (2012). The Relationship between Perception of Organizational Justice and Employee Empowerment in Industrial Town of Rasht, Journal of Basic and Applied Scientific Research, 2(11), PP. 11690-11695

Siglero, H \& Pearson, C.M; (2000). Creating an Empowerment Culture: Examine the Relationship between Organizational Culture and Perception of Empowerment, Journal of quarterly management, 5 (1), Pp. 27-52.

Simon, J. C., \& Soliman, K. S. (2003). An Alternative method to measure MIS faculty teaching performance. International Journal of Educational Management, 17 (5), pp. 195-199

Smith J., (2000). Empowerment People, London Kurgan, P4.

Taghavifard, M, Zahedi Adib, M and Torabi, M., (2007). The role of information technology in enterprise resource planning. Tadbir Jornal, 18 (186),pp. 33-37

Tarokh, M.J and Ommi, A.A (2002). Information technology and software exports, emissions-free tricks Messengers.

Vares, H., (2008) .emersion Information Technology, Tadbir Journals, No 87, 
Veten, D. A and Cameron, K.S. (2008). Enable employees. Translate Badrodin Orai Yazdani. Tehran. Management Education and Research Institute

Williamson Keren ,Williams Kristy J(2011). Organisational justice, trust and perceptions of fairness in the implementation of agenda for change, Radiography,17 (1), pp. 61-66.

Yazdanpanah, M.A., (2005). Impact of information technology on business empowerment. Second Symposium of employment and higher education.

Yilmaz, K., \& Tasdan, M. (2009). Organizational citizenship and organizational justice in Turkish primary schools. Journal of Educational Administration, 47 (1): 108-126.

Zargar, Mahmood (2009). Principles of Information Technology, Tehran, optimal. 